I Universidade Federal de Pelotas (UFPel), Programa de Pós-Graduação

m Sociologia, Pelotas, RS, Brasil

elaineleite Io@gmail.com

https://orcid.org/0000-0003-I402-3839

Elaine da Silveira Leite'

\title{
AUTOAJUDA FINANCEIRA: GOVERNAMENTABILIDADE NEOLIBERAL E A PRODUÇÃO DE SUJEITOS
}

Fridman, Daniel. (2017).

Freedom from work: embracing financial self-help in the

United States and Argentina. Standford: Standford

University. ${ }^{\mathrm{I}}$

Freedom from work: embracing financial self-help in the United States and Argentina, publicado em 2017 pela Standford University Press - cuja tradução, lançada em maio de 2019 pela Siglo XXI sin trabajar: una sociología del emprendedorismo, la autoayuda financiera y el nuevo individuo del siglo XXI - é leitura fundamental para antropólogos e sociólogos econômicos que se interessam por temáticas que interseccionam questões sobre economia e cultura, neoliberalismo e construção de sujeitos econômicos.

Daniel Fridman apresenta aos leitores o universo da autoajuda financeira, seus produtos e sociabilidades, apontando suas implicações no dia a dia de pessoas norte-americanas e argentinas de classe baixa e média que, motivadas pelas técnicas da autoajuda, passam a empregar ferramentas de cálculo em busca da liberdade financeira. Nesse sentido, oferece uma refinada análise de como sujeitos econômicos são constituídos na sociedade contemporânea.

No Brasil, o segmento conhecido como autoajuda financeira é classificado também como literatura de finanças pessoais. Os escritores mais notórios são considerados gurus - e a ascensão desse setor marca o surgimento de um circuito de consultores financeiros para indivíduos e famílias que vem crescendo vertiginosamente no país. Aqui, os consultores mais famosos se tornam figuras frequentes nos diversos órgãos da mídia, além de se destacar por vender livros, palestras, cursos e vídeos sobre o assunto (Leite, 
20I I, 20I7). Em geral, as orientações desse ramo enfatizam a educação financeira, sendo que a ideia "faça com que seu dinheiro trabalhe para você, não trabalhe para o seu dinheiro", ${ }^{2} \mathrm{co}-$ mo propõe Fridman (p. 32), se torna o principal mantra desse universo.

Nesse segmento, observa-se a relevância de Pai rico, pai pobre: o que os ricos ensinam a seus filhos sobre dinheiro (I997), escrito por Robert Kiyosaki e Sharon Lechter, que deu origem a diversos produtos, em especial o jogo de tabuleiro Cashflow (ou sua tradução, Corrida dos Ratos). Esse se constituiu num dos principais focos do trabalho de Fridman, por se tratar de ferramenta que tanto ajuda os leitores a se reunir em grupos quanto estimula os indivíduos a mudar sua atitude financeira.

Pai rico, pai pobre, que também é considerado um marco na literatura de finanças pessoais no Brasil (Paula \& Wood Jr., 2003; Leite, 20II, 20I7), apresenta seis lições que, segundo os autores, ajudarão qualquer pessoa a enriquecer. Nele, o "pai rico", que nunca concluiu o ensino médio, é quem vai ensinar os passos para a liberdade financeira. O livro procura estabelecer um modelo sobre a diferença entre ativo e passivo, sempre fazendo uso de dualidades, como demonstram os seguintes jogos de ideias: rico/pobre, risco/segurança, empreendedorismo/ estabilidade, inteligência/medo e razão/emoção (Leite, 20II, 20I7).

É possível constatar o empenho dos autores em consolidar a ideia de "homem rico" em um homem simplesmente inteligente, que sabe colocar o dinheiro a seu próprio serviço, não se tornando, assim, seu escravo. Dessa forma, legitima-se o mantra referido, fortalecendo uma lógica social que implica a incorporação de técnicas capazes de permitir aos indivíduos transformar-se para alcançar a liberdade financeira.

Desse modo, a grande inovação do trabalho de Fridman está na análise e descrição etnográfica articulada a uma discussão teórica sobre a ascensão do neoliberalismo - ainda cara aos teóricos sociais, mas que Fridman consegue articular teórica e empiricamente ao apresentar a autoajuda financeira como um conjunto de tecnologias do eu (Foucault, I988) e ao aludir à noção de performatividade econômica (Callon, I998), bem como de governamentabilidade (Foucault, 2008) para explorar a construção do "eu neoliberal".

O livro, fruto do trabalho de doutorado de Fridman, expõe os dados das pesquisas etnográficas realizadas em Buenos Aires e Nova York, em especial nos encontros de jogadores de Cashflow, bem como as articulações e os desdobramentos de seus principais interlocutores, seja na organização do Financial Freedom Argentina ou nas discussões de fóruns online.

As dinâmicas observadas por Fridman dão origem às ações e rotinas dos sujeitos que passam a desenvolver uma inteligência financeira associada a atitudes práticas, envoltas pela ideia de liberdade, que dão forma e conteúdo ao "empreendedor de si" (Foucault, 2008). Tal liberdade financeira, de acordo com Fridman, tem dupla conotação: primeiramente, significa "não 
ter que trabalhar para obter renda" ( $p$. 5); ao mesmo tempo, é "uma condição interna do eu, em virtude da qual o indivíduo deve superar seus medos para assumir riscos econômicos" (p. 5).

A riqueza da autoajuda financeira é a eficácia de seus produtos, pois as técnicas advindas da autoajuda - as sociadas às ferramentas de cálculo e aos princípios de liberdade, autonomia e abundância propalados por esse setor - reforçam a ideia de que os indivíduos só vão alcançar a meta desejada se realmente tentarem modificar as regras do jogo e adaptá-las à vida real. Isto é, sair da corrida dos ratos e adentrar o quadrante da independência financeira.

Os jogadores/leitores, portanto, são levados a refletir sobre suas atitudes em relação ao estilo de vida, ao trabalho e à situação financeira. Desse modo, passam a fazer uso de tabelas e cálculos matemáticos para a organização do orçamento, buscando resolver questões econômicas do dia a dia. Assim, Fridman nos mostra que a fabricação de sujeitos econômicos "que opera no mundo da autoajuda financeira não é um processo de cima para baixo, de políticas poderosas realizadas por instituições, mas algo que acontece diariamente" (p. 9).

A produção do "eu neoliberal" evoca a importância da educação financeira, isto é, uma educação instrumental que deve estimular habilidades financeiras relacionadas ao mundo real: "Kiyosaki acredita que as habilidades adquiridas na escola são inúteis quando se trata de alcançar a liberdade financeira" (p. 4I). Em tempos de hostilidade ao conhecimento científico e aos intelectuais, o livro de Fridman também abre espaço para refletir sobre a ascensão do neoliberalismo associado à emergência dessa educação financeira.

Assim, autoajuda financeira e educação passam a ser vistas e legitimadas pela lente do neoliberalismo. A produção desse homo oeconomicus subjetivamente confronta o saber acadêmico; ao mesmo tempo, os autores desses best-sellers tornam-se produtores de teorias sociais que fornecem explicações acessíveis sobre o funcionamento do mundo somadas a conselhos e técnicas de como agir, operando como um componente sociológico ( $p$. 24), conforme exemplifica Fridman ( $p$. I5-I6):

Kiyosaki desenvolveu uma teoria social popular da transição entre o período industrial ou corporativo do capitalismo e o estágio final, financeiro ou neoliberal (com rótulos, lembre-se, de "era industrial" e "era da informação"). A recomendação fundamental para a era atual, diferentemente do que a maioria dos livros de autoajuda corporativa propõe, é que os indivíduos elaborem um plano para que, com o tempo, possam deixar o emprego e receber "renda passiva" dos seus investimentos.

Fatores como incerteza e riscos começam a ser lidos como ativos positivos em contraponto às ideias de estabilidade e previsibilidade que figuraram como características do modelo capitalista do período industrial. Ou seja, a instabilidade passa a ser encarada como autonomia individual, 
e a incerteza, como elemento motivacional. Assim, essa teoria se torna legítima e popular, pois vem acompanhada de técnicas motivacionais, orientações e instrumentos de cálculo.

Neste contexto marcado por crises financeiras, vulnerabilidades das relações de trabalho, crescente desemprego e avanço do trabalho informal, a temática do empreendedorismo é incorporada e, ao mesmo tempo, retroalimenta a autoajuda financeira, já que tomar uma atitude e rever a posição atual no trabalho são consideradas atividades empreendedoras, que requerem a entrada no mundo da instabilidade e da incerteza (Leite, 20I I, 20I7). Desse modo, além do caráter performático da autoajuda financeira, Fridman apresenta o modo como seus interlocutores passam a se engajar neste mundo, ao apontar como empresas de marketing multinível entram em sintonia com a autoajuda financeira e reforçam a busca pela liberdade financeira, transformando os indivíduos em agentes autonômos, que superam seus medos e assumem riscos.

Isso posto, o indivíduo é tido como o único responsável por seu sucesso ou fracasso. Assim, Fridman esmiúça a construção do sujeito político neoliberal ao oferecer "um ângulo diferente para observar essas mudanças" trazidas pelo neoliberalismo, que nos "permite ver as tribulações de pessoas que vivem não apenas sujeitas a novas condições econômicas estruturais, mas também expostas a livros populares" (p. I77). Isto é, os produtos da autoajuda financeira fornecem as técnicas necessárias para converter os su- jeitos em objetos imaginados pela governamentabilidade neoliberal (p. I4).

Daniel Fridman é sociólogo, graduado pela Universidade de Buenos Aires (Argentina) e doutor pela Universidade de Columbia (EUA). Atualmente, é professor-assistente do Departamento de Sociologia e do Teresa Lozano Long Institute of Latin American Studies da Universidade do Texas, Austin.

$$
\begin{array}{r}
\text { Recebida em I6/09/20I9 } \\
\text { Revista em I7/06/2020 } \\
\text { Aprovada em 22/07/2020 }
\end{array}
$$




\section{NOTAS}

I Há uma edição argentina, de 20I9: El sueño de vivir sin trabajar: una sociología del emprendedorismo, la autoayuda financiera y el nuevo individuo del siglo XXI. Trad. Elena Odriozola. Buenos Aires: Siglo XXI Editores. [NE]

2 Todas as citações diretas contidas nesta resenha são traduções livres elaboradas pela autora.

Elaine da Silveira Leite é professora de sociologia do Programa de Pós-Graduação em Sociologia (UFPel). É doutora em sociologia pela Universidade Federal de São Carlos com doutorado sanduíche na New York University, no Departamento de Artes e Políticas Públicas. Atua na área da sociologia econômica e das finanças, já publicou pela Lexington Books e é atualmente uma das coordenadoras do GT de Sociologia Econômica da SBS. 


\section{REFERÊNCIAS BIBLIOGRÁFICAS}

Callon, Michel. (1998). The embeddedness of economic markets in economics. In: The laws of the markets. Oxford: Blackwell.

Foucault, Michel. (2008). Nascimento da biopolítica. Curso no Collège de France (1978-1979). São Paulo: Martins Fontes.

Foucault, Michel. (I988). Technologies of the self. In: Martin, Luther H.; Gutman, Huck \& Hutton, Patrick H. (eds.). Technologies of the self. Amherst: University of Massachusetts, p. 16-49. Leite, Elaine Silveira. (2017). A ressignificação da figura do especulador-investidor e as práticas de educação financeira. Civitas: Revista de Ciências Sociais, I7, p. II4-I30.

Leite, Elaine Silveira. (20II). Reconversão de habitus: o advento do ideário de investimento no Brasil. Tese de Doutorado. PPGS/Universidade Federal de São Carlos. Disponível em <https:// repositorio.ufscar.br/bitstream/handle/ufscar/6678/4III.pdf $>$. Acesso em 30 out. 2018.

Paula, Ana Paula Paes de \& Wood Jr., Thomaz. (2003). Viagem epistemológica às livrarias dos aeroportos. Revista Administração em Diálogo, 5, p. 77-86. 